\title{
A Novel Technique for the Damage Control of Huge Diaphragmatic Injuries
}

\author{
Boris Kessel MD' ${ }^{1}$, Victor Reva MD PhD², Daniel Sheffer $\mathrm{MD}^{1}$ and \\ Tal Hörer MD PhD³ \\ 'Surgical Division, Hillel Yaffe Medical Center, Hadera, Israel \\ ${ }^{2}$ Kirov Military Academy, Sanct Petersburg, Russian Federation \\ ${ }^{3}$ Division of General and Vascular Surgery, Faculty of life science, Orebro University, Sweden
}

\begin{abstract}
Background: Diaphragmatic injuries are rare in trauma victims, and mostly located on the left side. The standard approach is primary closure, using non-absorbable heavy interrupted sutures. Right-sided injuries are protected by the liver and such repair is not mandatory. However, closure of large defects, not suitable for primary suture, remains a challenging problem, especially in a military setting or in severely multiple-organ injured patients. Up until now, the single surgical solution in such situations is usage of absorbable mesh.

Methods: The feasibility of a damage control closure technique for huge traumatic diaphragmatic injury was evaluated.

Results: After creation of large diaphragmatic defects in an animal model, the defects were closed with an appropriately sized plastic (Bogota) bag and using a large abdominal pad, accordingly. The total procedure time was about 3 min and no chest re-protrusion was observed until completion of the experiment.

Conclusions: This novel method is likely to be safe and simple to use as a damage control method and should be further investigated in proper models and clinically.
\end{abstract}

Keywords: Damage Control; Diaphragmatic Injury; Temporary Closure

Received: 22 January 2020; Accepted: 12 February 2020

\section{INTRODUCTION}

Traumatic diaphragmatic injuries occur in $0.5 \%$ of trauma patients. They mostly result from penetrating injuries and are predominantly located on the left side [1]. The standard approach to diaphragmatic injuries in a damage-control setting is primary closure, using nonabsorbable heavily interrupted absorbable sutures. Right-sided injuries are protected by the liver, and such repair is not mandatory [2]. Closure of large defects not suitable for primary suturing remains a challenge, especially in military settings or for critically ill or hemodynamically unstable trauma patients. Currently, the sole

\section{Corresponding author:}

Boris Kessel MD, Surgical Division, Hillel Yaffe Medical Center, Sea Road 2, Hadera, Israel.

Email: bkkessel01@gmail.com

(C) 2020 CC BY 4.0 - in cooperation with Depts. of Cardiothoracic/ Vascular Surgery, General Surgery and Anesthesia, Örebro University Hospital and Örebro University, Sweden surgical solution in such cases lies in the use of absorbable mesh [3]. However, the insertion of mesh often requires complex anatomical dissections, including mobilization of the entire diaphragm, and identification of esophageal and aortic pleura. It is time consuming and demands the presence of a high level of expertise. In the context of damage-control surgery, the prevention of abdominal-organ re-protrusion to the chest should be achieved as quickly as possible.

The aim of this report is to explore the utility of Bogota bags or, alternatively, abdominal pads, for temporary diaphragmatic closure in an animal model as part of the damage-control concept.

\section{METHODS}

Two anesthetized, ventilated, instrumented, and normovolemic pigs were used to evaluate the feasibility of the technique. After creation of large diaphragmatic defects, using a scalpel and scissors in an identical fashion, a same-sized left diaphragmatic defect was created in both pigs (Figure 1). In the first pig, the defect was 


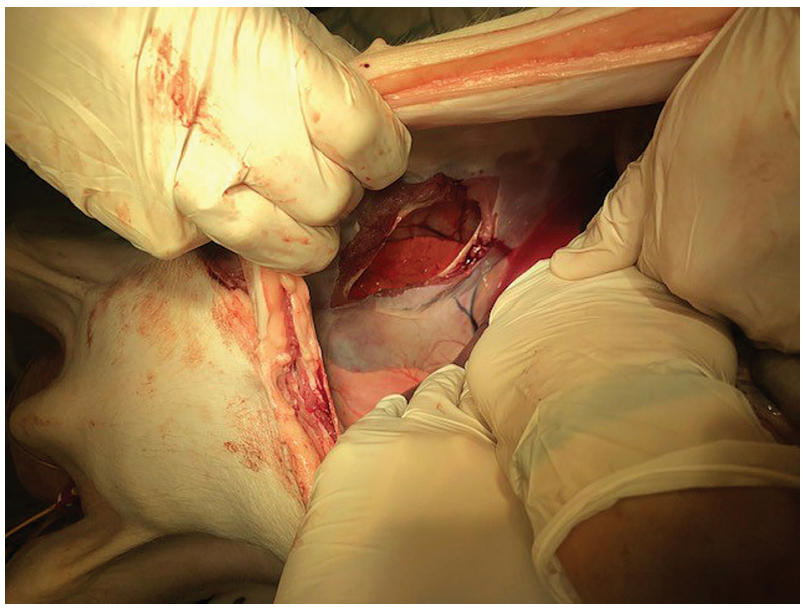

Figure 1 Creation of the diaphragmatic defect.

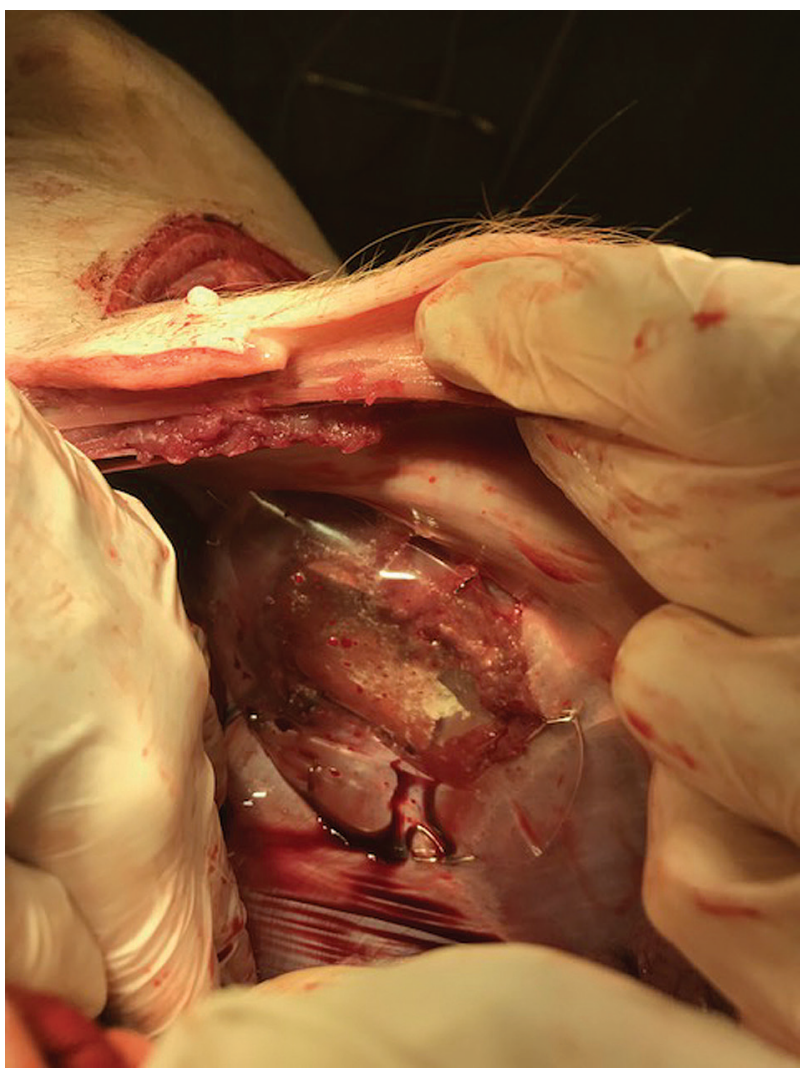

Figure 2 Closure of the defect using a Bogota bag.

closed with an appropriately sized plastic (Bogota) bag, fixed to the diaphragm with skin staples (Figure 2). The total time for the procedure was set at about $3 \mathrm{~min}$. In the second pig, the diaphragm edges were clamped with long Allis forceps, and the defect was covered using a large abdominal pad and sewn in with a few interrupted nylon zero sutures (Figure 3).

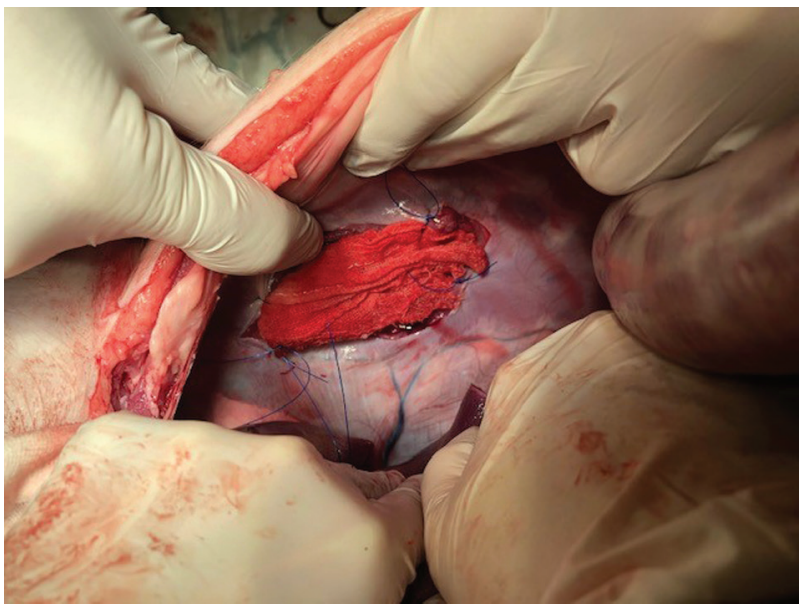

Figure 3 Closure of the defect using an abdominal pad.

\section{Ethical Approval}

The study was conducted in the frame of DSTC exercises, as approved by the regional ethical committee; the animals were euthanized immediately after completion of the experiment. The use of animals was according to the ethical rules and regulations of the Swedish government and to EU animal laws.

\section{RESULTS}

The total procedure time turned out to be about $3 \mathrm{~min}$. In both cases, the closure was not hermetic, but no chest re-protrusion was observed for a period of $2 \mathrm{~h}$ after completion of the experiment.

\section{DISCUSSION}

Diaphragmatic injuries are rare, and compounded only in about $0.5 \%$ of all abdominal injuries [4]. The most common mechanism involved in diaphragmatic tear is thoraco-abdominal penetrating injury [5]. The conventionally accepted surgical solution for such perforation is simple closure using heavily interrupted sutures. This technique is very simple and fast, and does not require special surgical skills. Moreover, right-sided diaphragmatic injuries do not entail mandatory closure since the liver usually safely prevents the protrusion of abdominal organs into the chest cavity. In rare cases, the defect in a diaphragm is very large, usually due to high-velocity missile injuries in war or significant blunt-trauma mechanisms, such as a fall from height or a road-traffic accident [6]. During a high-impact event, the tear usually occurs in the embryologically weakest posterior-lateral part of the diaphragm [7]. In the case of a large diaphragmatic defect that is not suitable for primary suturing, the only acceptable surgical repair consists of the use of prosthetic mesh [8]. In some cases of delayed diagnosis, repair may be achieved laparoscopically or thoracoscopically $[9,10]$. In most patients, the open 
abdominal approach is mandatory due to the high incidence of associated intra-abdominal injuries. However, such repairs are time consuming and require a high level of expertise [9]. Moreover, all the techniques described previously are inappropriate in the setup of damagecontrol laparotomy, especially taking into account that a significant portion of diaphragmatic injuries are associated with multiple concomitant injuries [11].

The main purpose of the method is to show the feasibility of prevention of the re-protrusion of abdominal organs after the completion of a damage-control laparotomy, which includes achieving adequate hemostasis, reducing herniated content to the abdominal cavity, and preventing contamination. Rapid evaluation of the diaphragmatic injury and inspection of the surrounding area permit selection of the best way of achieving temporary diaphragm closure. If there is no significant hematoma or persistent oozing in the left sub-diaphragmatic space, the edges of the diaphragm are clamped with long Allis or Babcock forceps, and an appropriate piece of plastic Bogota bag is secured to the diaphragm using skin staples or a few interrupted sutures.

The advantages of this approach are that it enables observation of the presence of accumulated blood in the chest, and the option of leaving the Bogota bag in place for 2-3 days if the re-laparotomy is delayed for other reasons. Another possibility for temporary closure lies in the use of a large abdominal pad, fixed to the diaphragm in the same fashion. The technique also allows proper counter compression in case the left sub-diaphragmatic space needs to be packed. Moreover, although this option was not evaluated in the experiment, the sutured diaphragm abdominal pads may be covered by an "internal" Bogota bag in order to prevent potential adherence of the small bowel loops to the pads.

\section{CONCLUSIONS}

This is a novel technique for temporary diaphragmatic closure. The method is likely to be safe and simple to use. Further investigation may enable it to be included in the routine surgical damage-control arsenal.

\section{Ethics Statement}

(1) All the authors mentioned in the manuscript have agreed to authorship, read and approved the manuscript, and given consent for submission and subsequent publication of the manuscript.

(2) The authors declare that they have read and abided by the JEVTM statement of ethical standards including rules of informed consent and ethical committee approval as stated in the article.

\section{Conflicts of Interest}

The authors declare that they have no conflicts of interest.

\section{Funding}

The authors received no financial support for the research, authorship, and/or publication of this article.

\section{Author Contributions}

All authors have substantially contributed to the study and manuscript writing.

\section{REFERENCES}

[1] Furák J, Athanassiadi K. Diaphragm and transdiaphragmatic injuries. J Thorac Dis. 2019;11(Suppl 2):S152S157.

[2] McDonald AA, Robinson BRH, Alarcon L, et al. Evaluation and management of traumatic diaphragmatic injuries: A practice management guideline from the Eastern Association for the Surgery of Trauma. J Trauma Acute Care Surg. 2018;85(1):198-207.

[3] Dirican A1, Yilmaz M, Unal B, et al. Acute traumatic diaphragmatic ruptures: a retrospective study of 48 cases. Surg Today. 20115;41(10):1352-1356.

[4] Mahamid A, Peleg K, Givon A, et al. Blunt traumatic diaphragmatic injury: a diagnostic enigma with potential surgical pitfalls. Am J Emerg Med. 2017;35(2): 214-217.

[5] D'Souza N, Clarke D, Laing G. Prevalence, management and outcome of traumatic diaphragm injuries managed by the Pietermaritzburg Metropolitan Trauma Service. Ann R Coll Surg Engl. 2017;99(5):394-401.

[6] Sacco R, Quitadamo S, Rotolo N, Di Nuzzo D, Mucilli F. Traumatic diaphragmatic rupture: personal experience. Acta Biomed. 2003;74 Suppl 2:71-73.

[7] Chughtai T, Ali S, Sharkey P, Lins M, Rizoli S. Update on managing diaphragmatic rupture in blunt trauma: a review of 208 consecutive cases. Can J Surg. 2009; 52(3):177-181.

[8] Antoniou SA, Pointner R, Granderath FA, Köckerling F. The use of biological meshes in diaphragmatic defects an evidence-based review of the literature. Front Surg. 2015;2:56.

[9] Hanna WC, Ferri LE, Fata P, Razek T, Mulder DS. The current status of traumatic diaphragmatic injury: lessons learned from 105 patients over 13 years. Ann Thorac Surg. 2008;85(3):1044-1048.

[10] Lee JH, Han KN, Hong JI, Kim HK. A single-port videoassisted thoracoscopic surgery with $\mathrm{CO}_{2}$ insufflation for traumatic diaphragmatic hernia. Interact Cardiovasc Thorac Surg. 2019;29(5):808-810.

[11] Mihos P, Potaris K, Gakidis J, et al. Traumatic rupture of the diaphragm: experience with 65 patients. Injury. 2003; 34(3):169-172. 